\title{
O trabalho, a terceirização e o Legislativo brasileiro: Paradoxos e controvérsias
}

\author{
Work, outsourcing, and the Brazilian Legislature: Paradoxes and \\ controversies \\ trabajo, la subcontratación y el Legislativo brasileño: Paradojas y \\ controversias
}

\author{
Alfredo ASSUNÇÃO-MATOS ${ }^{1}$ \\ Pedro Paulo Gastalho de BICALHO \\ Universidade Federal do Rio de Janeiro, Rio de Janeiro, RJ, Brasil
}

Resumo O objetivo deste artigo é analisar o Legislativo brasileiro frente à terceirização como modelo de gestão e suas implicações quanto à precarização e à flexibilização do trabalho. Inicialmente, situamos algumas mudanças do mundo do trabalho na forma de exploração do capital humano advindas dos sistemas taylorista e fordista. Observamos a crise estrutural dos anos 1970 e seus efeitos nas relações entre trabalho e trabalhadores, com uma breve análise dos anos 1980, período em que houve a implantação da acumulação flexível do capital e, como consequência, uma radical transformação na área de tecnologia e a mundialização da economia. Discute-se o funcionamento do Legislativo brasileiro e conclui-se com apontamentos sobre o Projeto de Lei 4.330/2004, de autoria do deputado Sandro Mabel (PMDB-GO), cujo principal encaminhamento é a permissão da terceirização nas denominadas atividades-fim.

Palavras-chave:

Psicologia organizacional; trabalho; serviços terceirizados.

\section{Abstract}

The objective of this article is to analyze the Brazilian Legislature in relation to outsourcing as a management model and its implications for making work more informal and flexible. Initially, we situate some changes that occurred in the world of work in the form of exploitation of human capital, arising from the Taylor and Ford systems. We have analyzed the structural crisis of the '70s and its effects on relations between work and workers, with a brief analysis of the ' 80 s, when flexible capital accumulation was implemented, and as a result, globalization of the economy and a radical technological transformation took place. The article discusses the functioning of the Brazilian Legislature and concludes with notes on the Law 4.330/2004 Project, by Rep. Sandro Mabel (PMDB-GO), whose principal characteristic is to permit outsourcing in so-called end-activities. Keywords:

Organizational psychology; work; outsourced services.

\section{Resumen}

El objetivo de este estudio es el analizar el Legislativo brasileño ante la subcontratación como un modelo de gestión y sus implicaciones respecto de la precariedad y flexibilización del trabajo. Primeramente, se sitúan algunos cambios que ocurrieron en el mundo del trabajo en materia de explotación del capital humano, resultantes de los sistemas Taylor y Ford. Luego, se analiza la crisis estructural de la década de 1970 y sus efectos en las relaciones entre trabajo y trabajadores. Para ello, hicimos un breve estudio de la década de 1980, período en que hubo la implementación de la acumulación flexible del capital y, consecuentemente, una radical transformación en el área de la tecnología y la globalización de la economía. Se discute el funcionamiento del Legislativo brasileño y se concluye con comentarios referentes al Proyecto de Ley 4.330/2004, de autoría del diputado Sandro Mabel (PMDB-GO), cuyo principal encaminamiento es el permiso de la subcontratación en las denominadas actividades-fin.

Palabras-chave:

Psicología organizacional; trabajo; subcontratación de servicios.

Endereço para correspondência: Rua Siqueira Campos, 225 ap.901, Copacabana, Rio de Janeiro, RJ, Brasil 22031-071. Email: assuncao.coach@gmail.com 
$\mathrm{C}$ om o passar dos anos, o termo trabalho foi ampliado e se tornou parte do cotidiano da sociedade. As transformações do mundo do trabalho ocorreram de forma tão intensa que, segundo Antunes (2002), ampliaram-se e inseriram-se na estrutura produtiva, nas formas de representação sindical e política e, sobretudo, tiveram profunda repercussão na construção da subjetividade, alterando, assim, as formas de ser e estar no mundo.

Se pensarmos em uma sociedade cindida por trabalhadores e capitalistas, devemos analisar também as contradições existentes entre o trabalho e o capital. A busca por soluções "mais humanas" e diminuição de conflitos no mundo do trabalho faz emergir fenômenos ligados às relações de trabalho como chave para soluções nas organizações e nas relações profissionais como um todo.

[...] Vivemos em meio a um engodo magistral, um mundo desaparecido que teimamos em não conhecer como tal e que certas políticas artificiais pretendem perpetuar. Milhões de destinos são destruídos, aniquilados por esse anacronismo causado por estratagemas renitentes, destinados a apresentar como imperecível nosso mais sagrado tabu: $\mathrm{O}$ trabalho [...] participamos de uma nova era sem conseguir observá-la. Sem admitir e nem sequer perceber que a era anterior desapareceu. (Forrester, 1997, p. 7)

O conceito de trabalho é amplo e se modifica de acordo com as diferentes perspectivas epistemológicas. O sentimento de pertencimento àquilo que se produz e a satisfação com o trabalho realizado tornam-se muito particulares e alteram-se a partir do campo de visão do sujeito, podendo trazer ou não bem-estar e realização. Fontoura e Gunther (2015) conceituam o trabalho como a aplicação da atividade humana à produção de bens e serviços em proveito de outrem que o remunera. Godoy e Cruz (2010) apontam que, em geral, o trabalho é compreendido como todo o esforço físico ou intelectual com o objetivo de realizar algo. Em linhas gerais, propõe-se definir o trabalho como algo gratuito ou oneroso, advindo de um esforço físico ou mental e que pode beneficiar a si próprio ou a terceiros, com o objetivo de produzir algum serviço ou bem.

O trabalho é circunscrito de diferentes e controversas formas entre os campos da sociologia, da economia, da psicologia e da engenharia. De fato, são vários os conceitos do trabalho e as formas de analisá-lo. Segundo Lima (2010), a produção de bens é, por excelência, o trabalho: evoluiu da escravidão ao contrato e, contraditoriamente, ainda subsiste nas duas formas, eventualmente de modos sutis. Segundo Antunes (2002), para entendermos melhor como o trabalho se consolidou na contemporaneidade, faz-se necessário um apanhado histórico anterior ao século XX. E, ainda, uma posterior análise de como o conhecemos hoje - a partir do último século, em que emergiu com força e inovação.

De acordo com Huberman (2011), na Idade Média, a sociedade feudal era constituída por três classes: sacerdotes, guerreiros e trabalhadores, sendo que os trabalhadores produziam para as outras duas classes. $\mathrm{O}$ trabalho era agrícola, pois ainda não existiam fábricas nem usinas; quem governava era o clero e a nobreza (controlando as terras) e ofereciam à classe trabalhadora proteção e auxílio espiritual em troca do cultivo das terras. Com o passar do tempo, houve a necessidade de investir toda a riqueza acumulada, dando início à era mercantilista, às cruzadas e ao comércio. $\mathrm{O}$ aumento do comércio estava ligado diretamente ao crescimento das cidades: surgiram as primeiras empresas, a riqueza deixou de ser a propriedade de terras e passou a ser a acumulação - o que no feudo era inativo e imóvel passou a ser ativo e vivo; surgiram os primeiros aspectos de aparecimento da hoje denominada classe média - que vive da compra e da venda de produtos e que partilha com o governo sua fonte de riqueza -, que passou não somente a satisfazer suas necessidades, mas também a produz para atender à procura alheia (Huberman, 2011).

\section{O capital e a organização do trabalho}

Boltanski e Chiapello (2009), assim como Lima (2012), enfatizam a exigência do sistema capitalista de acumulação ilimitada do capital, tendo como foco a liquidez que transforma a produção de bens e serviços em moedas, e de moedas em novos investimentos - por meios formalmente pacíficos. Conceitua-se, assim, o capital de três maneiras: social, humano e produtivo. O capital social é a potencialização de atuação da sociedade em associar-se de forma singular; o capital humano são os valores, as atitudes e o conhecimento de um determinado grupo; e o capital produtivo é constituído pelos recursos tangíveis e intangíveis, capazes de gerar fontes de riqueza e, consequentemente, criar novos postos de trabalho, emprego e renda para a sociedade como um todo (Wegner \& Maehler, 2012). 
Antunes (1999) destaca o conceito de capital como acumulação flexível, voltada de forma prioritária para a produção de mercadorias e para a valorização do capital (moeda). O autor afirma, ainda, que o movimento que ocorre nos dias de hoje tem acarretado as mais diversas transformações no mundo do trabalho, impactando diretamente o cotidiano do trabalhador. A acumulação flexível (Antunes, 2002) contrapõe a rigidez fordista, pois se apoia na flexibilização dos processos de trabalho. Surgem novos setores e novas formas de prestação de serviços, além de um olhar voltado para a inovação em diversos setores (comercial, tecnológico e organizacional).

O fato de o capitalismo ter crescido em torno dos mercados financeiros e dos movimentos de fusões e aquisições de empresas multinacionais, as quais recebem, em sua grande maioria, incentivos fiscais dos governos aos quais se inserem, promoveu certo limite do sistema capitalista principalmente quando retratado na flexibilização e na precarização do trabalho, no aumento de doenças oriundas das más condições laborais, no aumento de suicídios, entre outros (Boltanski \& Chiapello, 2009).

A precarização é um processo que se articula com a pobreza, que vem crescendo mesmo nos países industrializados (Brito, 2000). Outros fatores que interferem no quadro de pobreza e de precarização são os denominados ativos sociais - salários, benefícios, bens e serviços - a que um indivíduo tem acesso por meio de seus vínculos sociais; além dos ativos culturais - educação formal e conhecimento cultural -, que permitem a um indivíduo desenvolver-se em seu ambiente.

A partir do início do século XX, sobretudo da segunda década, o binômio Taylorismo/Fordismo de origem a características como a produção em série, homogeneizada, em massa e verticalizada.

[...] Iniciamos, reiterando que entendemos o fordismo fundamentalmente como a forma pela qual a indústria e o processo de trabalho consolidaram-se ao longo deste século, cujos elementos constitutivos básicos eram dados pela produção em massa, através da linha de montagem e de produtos mais homogêneos; através do controle dos tempos e movimentos pelo cronômetro taylorista e da produção em série fordista; pela existência do trabalho parcelar e pela fragmentação das funções; pela separação entre elaboração e execução no processo de trabalho; pela existência de unidades fabris concentradas e verticalizadas e pela constituição/ consolidação do operário-massa, do trabalhador coletivo fabril, entre outras dimensões. Menos do que um modelo de organização societal, que abrangeria igualmente esferas ampliadas da sociedade, compreendemos o fordismo como o processo de trabalho que, junto com o taylorismo, predominou na grande indústria capitalista ao longo deste século. (Antunes, 2002, p. 25)

Vale ressaltar que a expansão e a industrialização em massa da indústria automobilística - praticamente autossuficiente, pois utilizava pouquíssimos recursos externos (autopeças, por exemplo) - mecanizou a mão de obra, reduziu o tempo de operacionalização do processo como um todo e aumentou radicalmente o ritmo de trabalho. De acordo com Antunes (1999), a subsunção do trabalho ao capital estava presente e consolidada.

No final da década de 1960 e início da década de 1970, no entanto, erigiu-se uma grave crise econômicasocial na qual, de acordo com Boltanski e Chiapello (2009), o capitalismo endogeneizou-se diante das reivindicações de diferenciações e de desmassificação, e foi então que tiveram início as diversificações na produção. Segundo Antunes (1999), a partir dessa crise, o mercado e a forma como ele iria se relacionar com a sociedade sofreram consideráveis modificações. O capital financeiro foi o foco dessas discussões e, desse modo, serviu como divisor de comportamento de posicionamento das empresas a partir dessa década. Para Harvey (1989), tal crise foi o reflexo do esgotamento do padrão de acumulação e de organização do binômio taylorismo/ fordismo, ao mesmo tempo em que se configurou como mais uma das crises cíclicas do capitalismo.

A partir dessas mudanças observa-se uma alteração no comportamento da forma de trabalho do indivíduo e também das organizações diante de tal mudança. De acordo com Boltanski e Chiapello (2009), teve início a mercantilização de determinadas qualidades dos indivíduos devido à entrada do capitalismo em setores da economia que até então não participavam do mercado. O turismo, as atividades culturais e os serviços pessoais, por exemplo, dependeriam da inclusão do sentido humano no processo de produção que deveria voltar a ser comercializada. Porém, junto com a humanização do processo, vingaria e se tornaria parte essencial da lógica de mercado o adensamento competitivo entre as organizações, trabalhando de forma diferenciada as qualidades interacionais dos indivíduos, contrapondo o paradoxo da complexidade da lógica das organizações: operar somente por meio das relações comerciais ou atribuir sentimentos, como o afeto, a essas relações de trabalho. 
Enquanto as relações de trabalho sofriam mutações em todas as esferas relacionadas ao capitalismo, a sociedade começava a sentir os efeitos de uma produção mais flexível e uma alteração visível das relações de trabalho. Antunes (2002) se refere a um modelo de produção flexível, o toyotismo, com algumas especificidades, como: foco na demanda de mercado; produção just in time - sistema de produção enxuto que visa o melhor aproveitamento do tempo, transferindo a terceiros grande parte do que anteriormente era produzido dentro dele; criação de estruturas horizontalizadas; organização do trabalho baseada em equipes e projetos; surgimento de controles de qualidade; e, por fim, a terceirização de parte da força de trabalho. Contudo, esse modelo vem sofrendo adaptações, sendo mesclado com práticas oriundas do taylorismo/fordismo e diferentes filosofias (Bernardo, 2009). As mudanças técnicas, assim, forçam os empregadores a estabelecer um relacionamento mais cooperativo com o trabalho (Antunes, 1999).

Essas mudanças ocorreram porque se tornou inviável para as empresas manter modelos econômicos que não possuíssem altos níveis de rendimento, uma vez que emergem novos mercados, aumenta a concorrência e o comportamento dos trabalhadores se modifica, em parte devido ao aumento do acesso à educação, passando a coexistir maior articulação entre trabalhadores e sindicatos e representantes. Reivindica-se, então, melhores condições de trabalho e menor exploração do capital humano. Consequentemente, há uma alteração no objetivo da sociedade, que deixa de ser mecanicista, e inicia-se uma busca por melhor distribuição de renda e um novo sentido para o trabalho (Antunes, 2002).

Como o cenário exigia mudanças, inicia-se, na década de 1980, a implantação da acumulação flexível do capital (Antunes, 1999, 2002). Como consequência, ocorreu uma transformação na área da tecnologia, com a produção passando a ser mundial (mundialização), gerando o aumento da concorrência, da competitividade e do desemprego. O pensamento era adotar estratégias para controlar melhor a produção e, ao mesmo tempo, reduzir a quantidade da mão de obra, de modo a desarticular toda uma classe trabalhadora e fechar postos de trabalho, a fim de minimizar custos e viabilizar o negócio (Antunes, 2002). Essa seria a forma encontrada pelo mercado para sobreviver às grandes mudanças; porém, isso somente ocorreria com a efetiva implementação da Revolução Tecnológica, com a viabilização da flexibilização por meio de incremento tecnológico nas áreas de microtecnologia, tecnologias informacionais e inovações gerenciais.

As profundas transformações operadas com a tecnologia viabilizaram a mundialização do mercado qualitativa ou quantitativamente e que, segundo Antunes (1999), o modelo que até então era utilizado somente no Oriente, sofria a transferibilidade e adaptações para seu uso no Ocidente com uma menor culpabilização dos empresários, uma vez que os trabalhadores ocidentais recebiam aportes da lei e dos sindicatos.

Schaff (1990) refere que o Japão tinha o objetivo de até o final do século, eliminar o trabalho humano das fábricas automobilísticas, o Canadá de diminuir essa mão de obra em 25\% e os Estados Unidos em exterminar 35 milhões de empregos. Sennett (2009) complementa que, além do processo tecnológico, existe outra prática inserida nesse contexto que pode ser denominada como reengenharia, cuja principal consequência é a redução de empregos.

[...] As estimativas dos números de trabalhadores empregados que foram "reduzidos" de 1980 a 1995 variaram de um mínimo de 13 milhões a um máximo de 39 milhões. A redução tem tido uma relação direta com a crescente desigualdade, uma vez que só uma minoria dos trabalhadores espremidos para fora encontrou outro trabalho com os mesmos salários ou maiores. (Sennett, 2009, p. 56)

Com o surgimento de novas exigências e pré-requisitos no mundo do trabalho, os modos de trabalhar assumem outros contornos, com predomínio da atividade laboral temporária e terceirizada, inserida em um mercado mais dinâmico, com exigências de maior flexibilidade e polivalência. Tal fato opera transformações no trabalho como forma de produção, mas também na garantia de direitos a estes trabalhadores inseridos em novo modo de operar a força laboral.

O resgate da historicidade das relações de trabalho configura-se como estratégia discursiva que produz argumentação necessária para a proposta deste artigo, cujo objetivo é analisar o Legislativo brasileiro frente à terceirização como modelo de gestão e suas implicações quanto à precarização e a flexibilização do trabalho. Com a história, revela-se mais definidamente o processo que conduz ao aparecimento dos modelos de terceirização, especialmente quando o fenômeno de automatização da produção, disparado desde a Revolução Industrial, conjuga-se com redefinições nas estratégias de produção, demandando igualmente a promulgação 
de leis que flexibilizassem não somente as relações, mas principalmente os direitos trabalhistas previamente consolidados.

O surgimento da terceirização como modelo de gestão produz, também, a necessidade de regulamentação pelas normas jurídicas. Entra em cena o aparato legislativo como estratégia de promover, no campo legal, a flexibilização anteriormente anunciada, operacionalmente analisada neste texto pela via da terceirização.

\section{Notas sobre o método: O pesquisar no Legislativo Federal brasileiro}

No momento inicial da pesquisa, empreendeu-se busca utilizando como palavra-chave terceirização e, em um segundo momento, trabalho terceirizado, em mecanismos de pesquisas em sítios eletrônicos do Legislativo brasileiro: nas 27 assembleias legislativas das unidades federativas e, em nível federal, nas duas casas que compõem o Congresso Nacional. Desse modo, passou-se à leitura e à apreciação dos projetos apresentados para verificar, além da ementa, data de apresentação e situação atual de cada um, seus artigos e justificativas. A partir do levantamento de dados, foi possível construir tabelas e, em função da apropriação de um desses projetos pela mídia nacional, escolher um deles para análise, em tramitação na Câmara dos Deputados, levando em consideração também aqueles que a este foram apensados. Nosso interesse não se configura no desvelamento de minúcias, mas na compreensão de suas principais temáticas e racionalidades, para então prosseguir com a análise das relações de saber-poder engendradas, a partir da investigação de apenas um projeto.

A elaboração de leis (além de outras atribuições, como a fiscalização dos atos do Poder Executivo) compete ao Poder Legislativo, que no âmbito federal é constituído pelo Congresso Nacional que, desde 1891, é composto por duas Casas Legislativas autônomas: a Câmara dos Deputados e o Senado Federal. Integra, ainda, ao Poder Legislativo Federal, o Tribunal de Contas da União, órgão que auxilia o Congresso Nacional nas atividades de controle e fiscalização externa (fiscalização contábil, financeira, orçamentária, operacional e patrimonial da União e das entidades da administração pública direta e indireta, quanto à legalidade, legitimidade, economicidade, aplicação das subvenções e renúncia de receitas).

Com a proclamação da República, a tradição constitucional brasileira espelhou-se no modelo norteamericano para criar um Legislativo Federal bicameral, dividindo-o em duas vertentes, uma para representar os estados federados, com senadores eleitos pelo sistema majoritário, e outra para representar o povo, com deputados eleitos pelo sistema proporcional, formando, portanto, duas câmaras mutuamente revisoras. Foram exceções as Constituições de 1934 e 1937, que preconizavam o unicameralismo. A doutrina republicana entende que o bicameralismo é o sistema mais apropriado às federações ao apontar o Senado como a câmara representativa dos estados federados (Araújo, 2012).

A Câmara dos Deputados é constituída pelos representantes eleitos, em número proporcional ao da população de cada estado e do Distrito Federal, para um mandato de quatro anos. $\mathrm{Na} 55^{\text {a }}$ legislatura da história política do país - iniciada em 2015 -, a Câmara conta com 513 membros, cujo maior número de deputados é do estado de São Paulo, com 70 representantes, número máximo permitido pela constituição por estado. Os estados de menor população elegem o número mínimo de oito deputados previsto constitucionalmente (Câmara Federal, 2014).

O Senado Federal, embora também composto por membros escolhidos em eleição direta (mandato de oito anos), representa os interesses dos estados e do Distrito Federal como unidades da federação, independentemente do tamanho da respectiva população. Por isso, o número de senadores eleitos por estado e pelo Distrito Federal não é proporcional ao de habitantes, mas fixo: três por unidade da federação, totalizando, hoje, 81 membros. Os trabalhos de elaboração de leis se desenvolvem, basicamente, em duas fases distintas em cada Casa Legislativa: o momento em que os projetos tramitam nas atuais 20 comissões e, após, discussão e votação em Plenário (Senado Federal, 2015).

É no âmbito das comissões que os parlamentares, justamente por estarem reunidos em menor número que no Plenário, conseguem examinar minuciosa e cuidadosamente os projetos em tramitação, examinando aspectos técnicos, ético-políticos, sociais e jurídicos, identificando seus méritos e suas falhas, ouvindo autoridades e especialistas na matéria neles tratada, propondo-lhes eventuais alterações e aperfeiçoamentos, por meio de assessoria parlamentar direta ou por audiências públicas convocadas por um parlamentar. Quando conclui o exame de cada matéria submetida à apreciação, a comissão apresenta um parecer, recomendando aos demais parlamentares a aprovação, integral ou com alterações, ou a rejeição do projeto. 
O Plenário, para onde são dirigidos os pareceres oriundos das comissões legislativas, configura-se como a instância de decisão final sobre a maior parte das matérias apreciadas pelo Parlamento. É constituído pelo conjunto dos parlamentares que compõem a Casa (Câmara ou Senado), e as decisões tomadas em seu âmbito têm caráter definitivo e irrecorrível. Sendo o processo legislativo no nível federal do tipo bicameral, isto é, envolvendo a participação das duas Casas Legislativas, Câmara dos Deputados e Senado Federal, uma vez apreciado e aprovado um projeto ou proposta no Plenário de uma delas (chamada Casa iniciadora), ele será remetido à outra (Casa revisora), devendo passar também pelas fases de comissão e de Plenário. Depois, então, segue para sanção - parcial ou integral - ou veto presidencial.

Desse modo, o primeiro ato do processo de elaboração de uma lei é a apresentação, à Casa Legislativa, de um projeto, ou seja, de uma proposição legislativa. Embora o Regimento Interno da Câmara dos Deputados considere como proposição legislativa qualquer matéria submetida à deliberação da Casa, como emendas, pareceres ou recursos, apenas duas espécies efetivamente dão início ao processo legislativo: as propostas de emenda à Constituição e os projetos, esses últimos admitindo ainda três subespécies (de lei, de decreto legislativo e de resolução).

Os projetos de lei são proposições destinadas a criar novas leis ou a alterar as em vigor. Podem ser apresentados tanto por parlamentares, individual ou coletivamente (por meio de suas organizações próprias, como bancadas ou frentes parlamentares), quanto pelas comissões da Câmara, do Senado ou das duas Casas em conjunto, ou, ainda, pelo presidente da República - que dispõe de iniciativa concorrente com a dos parlamentares sobre temas em geral, mas detém competência privativa para a apresentação de projetos sobre certas matérias definidas pela Constituição Federal. Há também a possibilidade de iniciativa legislativa por parte do Supremo Tribunal Federal, dos Tribunais Superiores e do procurador-geral da República em relação a alguns assuntos específicos.

Nas comissões, entre o recebimento de uma proposição e a apresentação do parecer do relator (que constitui o primeiro voto), podem ocorrer reuniões de assessoria parlamentar e audiências públicas, com o objetivo de instruir e esclarecer o relator e os demais membros sobre as conveniências ou inconveniências da aprovação da matéria tratada na proposição, bem como suas controvérsias. Após a aprovação em uma comissão, o projeto segue para as demais consoantes ao tema. Uma vez encerrada a fase de apreciação pelas comissões, as proposições sujeitas à deliberação do Plenário são encaminhadas à Mesa com os respectivos pareceres, devendo aguardar sua inclusão na Ordem do Dia, ou seja, na pauta de deliberações do Plenário, onde primeiro inicia-se a fase de discussão e, em seguida, a votação.

A discussão é a fase em que a proposição é debatida pelos parlamentares inscritos. A inscrição para uso da palavra é feita perante a Mesa, antes de se iniciar a discussão, devendo cada debatedor declarar previamente se irá manifestar-se contra ou a favor da aprovação da proposição. Com isso, a Mesa pode organizar duas listas de oradores, concedendo a palavra alternadamente aos de uma e de outra posição, de modo que a um orador favorável à aprovação da matéria suceda, sempre que possível, um contrário. A fase de discussão de uma proposição sujeita à apreciação do Plenário é também o momento para os deputados apresentarem suas emendas ao projeto.

Para a votação, exige-se a presença mínima da maioria absoluta do total de membros votantes - o que equivale ao primeiro número inteiro superior à metade do total. Em caso de aprovação originariamente em uma das Casas e concluída a redação final, a proposição deverá ser remetida à outra Casa Legislativa para apreciação. Quando aprovada também na segunda Casa, há duas possibilidades: se com emendas, o processo deve retornar à primeira Casa para apreciação das alterações propostas; se na íntegra, o destino será o encaminhamento à presidência da República para veto ou sanção.

A sanção expressará a concordância do chefe do Poder Executivo com o conteúdo do projeto aprovado pelo Poder Legislativo. O veto, ao contrário, demonstrará sua oposição, total ou parcial, ao texto, que não poderá se transformar em lei exceto se o veto for rejeitado pelo Congresso Nacional. O presidente da República dispõe de 15 dias úteis para sancionar ou vetar projeto de lei (PL) que lhe tenha sido encaminhado pelo Legislativo. Após esse prazo, não tendo havido manifestação expressa em contrário, considerar-se-á sancionado o projeto (sanção tácita), devendo ser encaminhado à promulgação. O veto, se ocorrer, deverá fundamentar-se em razões de constitucionalidade ou de interesse público e ser comunicado pelo presidente da República ao presidente do Congresso Nacional, a quem competirá convocar sessão conjunta das duas Casas para sua apreciação. 
O veto presidencial a projetos de lei só poderá ser derrubado pelo voto secreto da maioria absoluta dos membros de cada uma das Casas do Congresso Nacional, hipótese em que o projeto deverá ser reenviado ao presidente da República para a promulgação, ato pelo qual a autoridade competente dá ciência ao público em geral de que uma lei foi aprovada e entrará em vigor (Pacheco, 2013).

Transformar um projeto em lei, portanto, é um processo complexo de formulação, negociação e votação, atravessado por relações de poder que fazem emergir paradoxos e controvérsias, capazes de promover o arquivamento de um projeto ou a promulgação de uma nova lei. E, como pontua Foucault (2002),

Discursos que podem matar, discursos de verdade e discursos que fazem rir. E os discursos de verdade que fazem rir e que têm o poder institucional de matar são, no fim das contas, numa sociedade como a nossa, discursos que merecem um pouco de atenção. (p. 8)

Transformar um PL em um objeto de pesquisa constitui-se, também, em um complexo processo, haja vista o caráter performativo e processual do caminho de tramitação que deve ser acompanhado pelo pesquisador. Pesquisa-se, portanto, não exatamente as modificações no texto legal, mas as racionalidades do PL 4.330/2004, de autoria do deputado Sandro Mabel (PMDB-GO), que "dispõe sobre o contrato de prestação de serviços a terceiros e as relações de trabalho dele decorrentes" (p.1).

\section{RESULTADOS E DISCUSSÃO}

\section{Dicotomia entre os discursos do processo de terceirização: Ferramenta de gestão ou práti- cas de precarização do trabalho?}

O fenômeno da terceirização originou-se nos Estados Unidos, logo após a eclosão da Segunda Guerra Mundial. Hoje, configura-se como uma técnica moderna de administração direcionada ao enxugamento das estruturas gerenciais, constituindo-se em uma prática integrante das novas formas de gestão, como a formação de redes organizacionais e de parcerias, permitindo às empresas concentrarem-se em suas atividades-fim.

A terceirização, também denominada mundialmente de Outsourcing - que significa "fonte de fora" - configura-se como um processo pelo qual a empresa opta em concentrar esforços no seu Core Business, podendo focar mais no mercado, tornando-se, assim, mais competitiva. Trata-se de uma técnica da administração que possibilita estabelecer um processo gerenciado de transferência, a terceiros, das atividades acessórias e de apoio ao escopo das empresas que é a sua atividade-fim, permitindo a elas se concentrarem em seu negócio, ou seja, no objetivo final.

Entre todas as possibilidades de inserção da terceirização no mercado, podemos dizer que:

[...] A terceirização é uma tecnologia de administração que consiste na compra de bens e/ou serviços especializados, de forma sistêmica e intensiva, para serem integrados na condição de atividade-meio à atividadefim da empresa compradora, permitindo a concentração de energia em sua real vocação, com intuito de potencializar ganhos em qualidade e competitividade. (Fontanella, Tavares, \& Leiria, 1994, p. 19)

Transferir as atividades para fornecedores especialistas, consequentemente detentores de uma tecnologia moderna e própria, liberaria, a princípio, a empresa contratante para concentrar seus esforços gerenciais em seu negócio principal, preservando e evoluindo em qualidade e produtividade, reduzindo custos e ganhando em competitividade. Assim, pontua-se que toda empresa terceirizada deva encontrar-se apta a desenvolver um trabalho de excelência nas organizações a que prestarão serviços. Com a terceirização, a empresa se concentraria em seu produto estratégico, naquilo que é capaz de fazer melhor, com competitividade e maior produtividade. As tarefas secundárias e auxiliares, realizadas por empresas que se especializaram de maneira mais racional e com menor custo não onerariam, desse modo, o processo produtivo.

O mundo contemporâneo aponta a necessidade de que as empresas estejam focadas em seus objetivos e que sua produtividade necessita de crescimento constante e melhoria na qualidade. A partir das análises de Heringer, Ramos e Santiago (2012), a terceirização ganha importância em um momento no qual as empresas precisam racionalizar recursos, redefinir suas operações, funcionar com estruturas mais enxutas e flexíveis. Assim, ela se apresenta como um dos instrumentos de auxílio à reestruturação organizacional, ao incremento da produtividade e da competitividade e à busca da identidade e comprometimento com a vocação da empresa. 
A crescente competitividade e a grande dificuldade que as empresas enfrentam em se manterem no mercado globalizado faz com que sejam reconhecidas diversas vantagens nesse processo. Na concepção de Araújo (2009), os principais benefícios da terceirização são as razões de ordem financeira: redução dos custos passíveis de enxugamento e economia na utilização dos recursos da empresa; de ordem tecnológica: a contratada disponibiliza à contratante todas as inovações tecnológicas que surgem no mercado; competitivas: a empresa que adere ao outsourcing torna-se mais ágil se concentrando nas questões realmente significativas; excelência operacional: concentração no essencial à evolução competitiva da empresa, sem abrir mão da qualidade nas atividades contratualmente delegadas; competência no negócio: a procura de maior competência no negócio justifica a entrega de funções de apoio, que pouco ou nenhuma intimidade têm com os negócios da empresa, caracterizando o mais forte benefício.

De acordo com Antunes (2002), a terceirização e tantos outros modelos inseridos no "mundo empresarial" são expressões de uma lógica societal, em que prevalece o capital sobre a força humana de trabalho e que, apesar de diminuir o trabalho vivo nas organizações, não o extingue por completo. Assim, aponta-se a controvérsia: será que a prática da terceirização, da forma como vem ocorrendo, não se tornou um subterfúgio para precarizar o trabalhador, agora denominado "terceirizado"? Acreditamos que a resposta seja complexa, com infinidades de situações e respostas, porém, identificaremos as que consideramos principais e que de certa forma servem de inspiração para as demais.

Dejours (1999) contextualiza que a terceirização em cascata constituirá uma quantidade considerável de reservas de trabalhadores que estarão fadados à precariedade constante, à má remuneração e a uma flexibilidade que os obrigariam a estar sempre procurando novos empregos em novas empresas. De modo geral, vários fatores contribuem para a precarização do trabalho terceirizado, entre os quais: emprego temporário (surgiu na década de 1970, com avanço considerável na segunda metade dos anos de 1980, e inclui estagiários e indivíduos contratados por prazo determinado); empregos por tempo parcial (ocorre quando o trabalhador é contratado para cumprir somente a metade de uma jornada, sendo o volume de trabalho o mesmo - alguns trabalhadores são contratados temporariamente e por período parcial, aumentando a fragilidade desta prática para o trabalhador); dualização dos assalariados (profissionais com as mesmas funções recebendo salários diferentes); processos de seleção/exclusão (diante das práticas de gestão, o profissional menos qualificado, com dificuldade de comunicação e com capacidades de empenho e adaptação comprometidas, se vê expurgado da concorrência por empregos melhores, submetendo-se a trabalhar em qualquer tipo de empresa). De acordo com Druck e Seligmann-Silva (2010) e Fileti (2009), houve uma redução de proteção aos trabalhadores e, com isso, um retrocesso social, o que possibilitou às empresas evitarem a coerção do direito do trabalho, tornado inaplicáveis os textos do Legislativo.

\section{Uma propositura legislativa para acelerar a precarização do trabalho}

Um PL que pretende ampliar a terceirização da mão de obra para todas as atividades de uma empresa tem gerado debates entre empresas, sindicatos, trabalhadores, pesquisadores e juristas. Discutiremos sobre os principais aspectos que envolvem o PL, além de sua tramitação entre as comissões que integram o Legislativo brasileiro.

O trabalho temporário está previsto na Lei 6.019/1974, a qual propõe que a contratação de mão de obra pode ser flexibilizada nas situações em que as contratações forem feitas por empresas terceiras (prestadoras de serviço). De acordo com o Departamento Intersindical de Estatística e Estudos Socioeconômicos [DIEESE] (2010), a terceirização se insere como fator de flexibilização da mão de obra, uma vez que a empresa contratante não terá custo com direitos trabalhistas, admissões, demissões, treinamentos e benefícios sociais, os quais serão responsabilidade da empresa terceirizada.

Atualmente, no Brasil, tramita no Legislativo o PL 4.330/2004, de autoria do deputado Sandro Mabel (PMDB-GO), que, entre suas várias proposições, muda e amplia o entendimento de que a contratação de empresas terceirizadas passaria a ser permitida não somente para as atividades-meio, mas também para as atividades-fim, o que hoje é ilegal. O autor da PL pontua que o texto surgiu da necessidade de regulamentação dessa relação de trabalho e que não haverá prejuízo para os trabalhadores.

O controverso PL aponta, de um lado, o ponto de vista econômico (que seria a constante busca das empresas pela maximização de lucros e redução de despesas), e, de outro, a perspectiva social (sendo a busca por lucros um impactante direto nas condições de trabalho dos empregados, em especial os terceirizados, pois têm seus 
direitos desrespeitados e são vistos pelo mercado como trabalhadores de segunda classe). Este PL, em caso de promulgação, alteraria diretamente a súmula 331 do Tribunal Superior do Trabalho (TST) que resguarda e protege os principais elementos normativos do instituto da terceirização trabalhista no Brasil.

Por se tratar de um PL que tramita há mais de 10 anos no Congresso Nacional e que somente ganhou a devida atenção dos responsáveis e da mídia a partir de 2013, houve grandes sugestões de alterações, devido à pressão da sociedade civil e dos sindicatos dos trabalhadores durante as votações na Câmara dos Deputados. A proposta percorreu os seguintes órgãos: Coordenação de Comissões Permanentes (CCP), Comissão de Desenvolvimento Econômico, Indústria e Comércio (CDEIC), Comissão de Trabalho, de Administração e de Serviço Público (CTASP), Comissão de Constituição e Justiça e de Cidadania (CCJC), Plenário (PLEN) e Mesa Diretora da Câmara dos Deputados (Mesa).

No dia 27 de abril de 2015, a Mesa Diretora da Câmara dos Deputados (Casa iniciadora) enviou ao Senado Federal (Casa revisora) a remessa (PL em inteiro teor) para tramitação visando à apreciação e, então, a aceitação ou o veto. As principais alterações propostas pelo PL 4.330/2004 são: estender a terceirização para atividadesfim e para qualquer atividade econômica; promover a responsabilidade subsidiária da empresa contratante quanto a condições de salubridade dos terceirizados; criar a quarteirização da mão de obra e "pejotização" ${ }^{2}$, entre outros. Sindicatos, trabalhadores e alguns parlamentares consideram o projeto uma grave ameaça ao direito do trabalho. Na prática, ele dilui a responsabilidade do empregador, acaba com a identidade das categorias profissionais e mitiga conquistas e garantias consolidadas, apontando para um caminho em direção a um passado de precarização do emprego e das condições de trabalho.

Identificamos que no decorrer dos anos houve mudanças no modo de operar do capitalismo; que, seguido de sequências de forças advindas da articulação dos trabalhadores perante o poder paulatinamente construído como resistência e enfrentamento às empresas, resultou em maior mobilização e transformação do posicionamento do trabalhador frente ao seu sentimento de (in)satisfação para com esse tipo de regime. Essa força de enfrentamento constante age sobre o capitalismo como uma mola propulsora pela luta de melhores condições de trabalho, ganho de qualidade de vida, reformas na legislação e melhoria da equidade entre as classes trabalhadoras, aumentando o poder de compra e, consequentemente, melhorando a qualidade de vida.

Vimos uma evolução da literatura da gestão empresarial em demonstrar uma maior preocupação com o indivíduo e sua qualidade de vida no trabalho, respondendo às demandas históricas dos direitos conquistados, da liberdade e da autenticidade crítica da forma de se organizar a sociedade. Esse movimento paradoxal do capitalismo - em que se busca o lucro, mas também se olha para o trabalhador -, faz o processo de renovação do capitalismo sofrer mudanças constantes, muitas vezes marcadas por controvérsias.

Vivemos momentos de instabilidade político-econômico-financeira e de seguridade social e novas formas de gestão passam a se configurar como estratégias para que os mercados se mantenham. Porém, afirma-se o paradoxo para o fato de que tais modelos devam coexistir com a manutenção da qualidade de vida e a promoção dos direitos sociais e trabalhistas. Tal paradoxo se apresenta em forma de um PL, que, segundo seus defensores, tem como objetivo proteger ainda mais os trabalhadores terceirizados. Projeto controverso: reconhece-se (e afirma-se), não obstante ao objetivo propagado, o perigo que advém de um discurso pautado na flexibilização do trabalho e que, na verdade, aponta para um processo de mais precarização.

O modelo de acumulação flexível, como admite Antunes (1999), traduz-se na intensificação dos níveis de exploração do trabalhador, o que vem ocorrendo com a crescente precarização das condições de trabalho, a qual assume forma privilegiada na terceirização. Conclui-se, portanto, que enquanto houver controvérsia, haverá a luta. Seguimos, enfim, lutando.

\section{REFERÊNCIAS}

Antunes, R. (1999). Os sentidos do trabalho: Ensaio sobre a afirmação e a negação do trabalho (2a ed.). São Paulo: Boitempo.

Antunes, R. (2002). Adeus ao trabalho? Ensaio sobre as metamorfoses e a centralidade do mundo do trabalho (8a ed.) São

Paulo: Cortez/Unicamp.

Araújo, L. C. G. (2009). Gestão de pessoas: Estratégias e integração organizacional (2a ed.). São Paulo: Atlas.

\footnotetext{
2 A "pejotização" é uma burla à legislação trabalhista em que, por meio da imposição pelo empregador da constituição de uma pessoa jurídica por parte do empregado, o primeiro se desonera de encargos sociais, considerados empecilhos à (maior) lucratividade (Magalhães, 2014).
} 
Araújo, P. M. (2012). O bicameralismo no Brasil: Argumentos sobre a importância do Senado na análise do processo decisório federal. Política \& Sociedade, 11(21), 83-135. doi: 10.5007/2175-7984.2012v11n21p83

Bernardo, M. H. (2009). Trabalho duro, discurso flexível: Uma análise das contradições do toyotismo a partir da vivência de trabalhadores. São Paulo: Expressão Popular.

Boltanski, L., \& Chiapello. O. (2009). Novo espírito do capitalismo. São Paulo: Martins Fontes.

Brito, J. C. D. (2000). Enfoque de gênero e relação saúde/trabalho no contexto de reestruturação produtiva e precarização do trabalho. Cadernos de Saúde Pública, 16(1), 195-204. doi: 10.1590/S0102-311X2000000100020.

Câmara Federal. (2014). Regimento interno da Câmara dos Deputados. Brasília: Câmara dos Deputados/Coordenação de Publicações.

Dejours, C. (1999). A banalização da injustiça social. Rio de Janeiro: FGV.

Departamento Intersindical de Estatística e Estudos Socioeconômicos. (2010). Terceirização e morte no trabalho: Um olhar sobre o setor elétrico no Brasil. Estudos \& Pesquisa, 50, 1-18.

Druck, G., \& Seligmann-Silva, E. (2010). As novas relações de trabalho, o desgaste mental do trabalhador e os transtornos mentais no trabalho precarizado. Revista Brasileira de Saúde Ocupacional, 35(122), 229-248.

Fileti, N. A. M. (2009). O princípio da proibição de retrocesso social. Revista Jus Navigandi, 14(2059).

Fontanella, D., Tavares, E., \& Leiria, J. S. (1994). O lado (des)humano da terceirização. Salvador: Casa da Qualidade.

Fontoura, J., \& Gunther, L. E. (2015). A natureza jurídica e a efetividade das recomendações da OIT. Revista de Informação Legislativa, 38(150), 195-204.

Forrester, V. (1997). O horror econômico. São Paulo: Ed.UNESP.

Foucault, M. (2002). Os anormais. São Paulo: Martins Fontes.

Godoy, F., \& Cruz, S. G. F. P. (2010). Artifício da captura e/ou limiar da ruptura? Reflexões sobre as trajetórias do cooperativismo na sociedade contemporânea capitalista. Revista de Psicologia da UNESP, 8(2), 152-167.

Harvey, D. (1989). A condição pós-moderna: Uma pesquisa sobre as origens da mudança cultural. São Paulo: Loyola.

Heringer, B. H. D. F., Ramos, C. S. D. S., \& Santiago, M. R. (2012). A díade vantagem e desvantagem: Estudo de caso de terceirização da área de recursos humanos. Revista de Administração da Fatea, 4(4), 81-92.

Huberman, L. (2011). História da riqueza do homem (23a ed.). Rio de Janeiro: LTC.

Lei 6.019, de 3 de janeiro de 1974 (1974, 3 de janeiro). Dispõe sobre o trabalho temporário nas empresas urbanas, e dá outras providências. Diário Oficial da União, Seção 1.

Lima, J. C. (2010). A terceirização e os trabalhadores: Revisitando algumas questões. Cadernos de Psicologia Social do Trabalho, 13(1), 17-26.

Lima, R. A. (2012). A lei geral de acumulação capitalista e as crises cíclicas. Leituras de Economia Política, 13(16), 87-110.

Magalhães, C. P. V. (2014). O fenômeno da pejotização na legislação trabalhista. Vianna Sapiens: Revista das Faculdades Integradas Vianna Júnior, 5(1), 84-111.

Pacheco, M. B. (2013). Como se fazem as leis. Brasília: Câmara dos Deputados.

Projeto de Lei n. 4330, de 26 de outubro de 2004 (2004, 24 de abril). Dispõe sobre o contrato de prestação de serviço a terceiros e as relações de trabalho dele decorrentes. Recuperado de http://www.camara.gov.br/proposicoesWeb/fichadetramitacao?i dProposicao $=267841$

Schaff, A. (1990). A sociedade informática. São Paulo: Brasiliense/Unesp.

Senado Federal. (2015). Regimento interno do Senado Federal. Brasília: Senado Federal/Coordenação de Publicações.

Sennett, R. (2009). A corrosão do caráter - Consequências pessoais do trabalho no novo capitalismo. Rio de Janeiro: Record.

Súmula no 331 do Tribunal Superior do Trabalho. Contrato de prestação de serviços: Legalidade. Res. 174/2011. Recuperado de http://www3.tst.jus.br/jurisprudencia/Sumulas_com_indice/Sumulas_Ind_301_350.html\#SUM-331

Wegner, D., \& Maehler, A. E. (2012). Desempenho de empresas participantes de rede interorganizacionais: Analisando a influência do capital social e da capacidade absortiva. Gestão \& Planejamento-G\&P, 13(2), 191-211. 